\title{
Language, partial truth, and logic
}

\section{Citation}

Elgin, Catherine Z. 2011. Language, partial truth, and logic. Analysis 71, no. 2: 313-322.

\section{Published Version}

doi:10.1093/analys/anq063

\section{Permanent link}

http://nrs.harvard.edu/urn-3:HUL.InstRepos:4889480

\section{Terms of Use}

This article was downloaded from Harvard University's DASH repository, and is made available under the terms and conditions applicable to Open Access Policy Articles, as set forth at http:// nrs.harvard.edu/urn-3:HUL.InstRepos:dash.current.terms-of-use\#OAP

\section{Share Your Story}

The Harvard community has made this article openly available.

Please share how this access benefits you. Submit a story.

\section{Accessibility}




\section{Language, Partial Truth, and Logic}

\section{Catherine Z. Elgin}

In Hard Truths, Elijah Millgram maintains that analytic philosophy rests on a mistake. ${ }^{1}$ It is committed to bivalence - the contention that every truth bearer is either true or false. As a result of this commitment, its views about logic and metaphysics are profoundly misguided. He believes that rather than restricting ourselves to two truth values, we should recognize a plethora of partial truths - sentences, beliefs, and opinions that are partly true or true in a way. These are located on a multidimensional continuum between truth and falsity. Millgram never says exactly what partial truth is. The closest he comes is 'Partial truth is the not fully articulated standard, or family of standards to which we hold [utterances, inscriptions and thoughts] in partial truth inferences' (108), where partial truth inferences are those used in cases where 'there is a recognized mismatch between representation and world - but not in any way that requires changing the representations' (108-9). A critical issue then is what constitutes such a mismatch. I will argue that Millgram's reasons for recognizing partial truths rest on untenable conceptions of logic, truth and language. Perhaps there are partial truths; perhaps recognizing them would enhance our logic or metaphysics. But Millgram's arguments fail to show it.

\section{Logic}

Recognizing that there can be some truth in sentences that as a whole are false is not unprecedented. Analyses by Ullian and Goodman ${ }^{2}$ and, more recently, Yablo ${ }^{3}$ reveal how a false sentence or proposition can be true about a particular item. 'The dog barks and the cat speaks French' is true about the dog, even though the conjunction as a whole is false. This does not undermine classical logic. Rather, such analyses reveal that truth about a particular subject matter is more fine grained than truth simpliciter. 'True about' preserves truth functional relations 
when indexed to a subject matter. If $p$ is true about the $\operatorname{dog}$ and $q$ is true about the $\operatorname{dog}$, then $p \&$ $q$ is true about the dog. To be sure, some analytic philosophers have misgivings about bivalence. Dummett maintains that intuitionistic logic would serve our needs better than classical, two valued logic. ${ }^{4}$ Lewis develops a five-valued 'logic for equivocators'. ${ }^{5}$ Millgram's charge is deeper. He contends that between hard truth and hard falsity, there are indefinitely many grades of partial truth along indefinitely many dimensions. 'There are always further ways one could want to hedge on what further inferences one is instructing oneself or others to draw; there are always further ways to hedge on how one's representation can be out of line with the facts without calling for correction. Consequently, there is no point in trying to accommodate the position . . . by adding on a shorter or longer list of truth values and going on as before.' (109) A multi-valued logic would not help.

Like Millgram, I believe that we often reason well using representations we know not to be true. Unlike Millgram, I consider such representations false. ${ }^{6}$ Granted, not every false sentence is cognitively valuable. Something has to be said about what makes a false representation epistemicaly effective. There is plenty to say, because truth is not the only dimension along which representations can be assessed for accuracy, epistemic adequacy, informativeness, and/or cognitive utility. As far as I can see, nothing about our capacity to use, our propensity to use, or our need (if indeed we have a need) to use such representations discloses anything about the acceptability or universality of classical logic, the proper approach to metaphysics, or the need to retain or abandon bivalence.

Millgram's orientation is practical. He asks 'What is logic for?' and argues that if we can discover the role that logic is supposed to play in our cognitive economy, we can figure out what sort of theory or practice could play that role. This is an entirely reasonable approach. Unfortunately, his answer is unfounded. The point of logic, he contends, is to prescribe rules of 
good reasoning. Indeed, he seems to think that according to analytic philosophers logic should prescribe all the rules of good reasoning. 'Deductive inference, and specifically the deductive logic taught in all those introductory classes, is real inference . ..: the closer a form of inference is to such deductive inference, the more real it is.' (3) He thus takes analytic philosophy to marginalize induction, abduction, analogical reasoning, and the like as not sufficiently 'real'. A survey of the literature would not bear this out. To take just one example, analytic philosophers have spilled oceans of ink discussing the raven paradox and the grue paradox. It is hard to see why they bothered if they did not consider inductive inference both real and important. Nevertheless, Millgram believes that by showing that lots of reasoning is not classical logical inference, he undermines the commitment to bivalence, and with it the tenability of analytic philosophy. Because he takes logic to consist of Laws of Thought, he thinks it can be undermined by showing that good reasoning - reasoning in accordance with the Laws of Thought - does not conform to first order classical logic.

Frege disagrees. He contends that logic consists of Laws of Truth - laws that account for the ways the truth value of one sentence bears on the truth values of others. ${ }^{7}$ He believes that knowing the relations in which truths and falsehoods stand to each other - e.g., relations of consistency and of consequence - is valuable in itself. I agree. Millgram does not. He contends that if analytic philosophers did not think that logic underwrites reasoning, we would have no incentive to take it as seriously as we do.

To appreciate the difference between the two positions, consider modus ponens:

$$
(p \&(p \rightarrow q) \rightarrow q) .
$$

Modus ponens displays truth functional relations among three truth bearers: $p, p \rightarrow q$ and $q$. On the face of it, it says nothing about what, or how, or indeed whether anyone should think. According to Millgram, however, modus ponens is supposed to be a guide for drawing 
conclusions. On his interpretation, if $S$ believes that $p$ and believes that if $p$ then $q$, then $S$ should conclude that $q$. But logic says no such thing. The move from 'true' to 'believes true' is fraught with peril; for it is easy to believe something true when it is not. ${ }^{8}$ Moreover, even if the inference is sound and $S$ believes the premises, she may have reason to reject the conclusion. Upon realizing that she believes that $p$ and that she believes that if $p$ then $q$, $S$ may conclude that, since $q$ strikes her as preposterous, one of her premises is false. She may conclude that there must be a previously undetected equivocation in the argument. She may conclude that she has discovered an antinomy, suggesting that her entire conceptualization of the issue is defective. Or she may simply be bewildered and suspend judgment on the whole matter. Logic just tells her that $p$ conjoined with $p \rightarrow q$ entails $q$. It enables her to recognize that her opinions are jointly inconsistent. It does not even tell her that there is anything wrong with being inconsistent. ${ }^{9}$

Nor does logic insure that if the argument is sound and on the basis of it $S$ concludes that $q$, she has reasoned well. Millgram maintains that the value of classical logic, when one can use it, is that it is mechanical. It may be difficult to discover a proof, but if the proof is valid, the truth of the inputs assures the truth of the outputs. Judgment is not required. He is right of course, that it is often reasonably straightforward to ascertain that the logical form of an argument is impeccable, so the truth of the inputs guarantees the truth of the outputs. But that does not by any means insure that the reasoning is good. If one wants to reason well about a topic, one needs not just true premises, but premises that are relevant, cogent, and apt. One needs premises at the proper level of generality, and premises that bear on the topic at issue. One needs to block inferences that are misleading or that give rise to misleading implicatures. And so forth. Logic alone does not, and does not purport to, provide any of that. So Millgram's contention that judgment is called for when and only when we are reasoning with partial truths is false (27). Reasoning well always requires judgment. 


\section{Language}

A major motive for recognizing partial truths is an appreciation of how sparse our vocabulary is. We do not have a name for every individual or a predicate for every extension. Given the limits on our cognitive abilities, we would be unable to function if we did. For our minds would be cluttered with finely differentiated terms that we rarely had occasion to use. So we coin terms only for the individuals and extensions that matter to us. But it would be highly inconvenient, if not disastrous, if we had no way to refer to items that lack literal labels. Such items would, Millgram argues persuasively, be effectively invisible. Having no way to refer to them, we would have no way to hold them in mind and think about them. By building in flexibility we accommodate our need to say and think about a vast and motley collection of items using only a relatively sparse vocabulary. We use our terms loosely to characterize things in the neighborhood of their strict, literal applications. The term 'red' then is available not just for characterizing things like fire trucks and traffic lights, but also shades of hair and shades of wood. We extend the range even further by introducing words like 'sort of', suffixes like '-ish', and comparatives. This enables us to characterize the European deer as sort of red, or as reddish, or as redder than the American deer.

Millgram's explanation of the flexibility and adaptability of ordinary language is that sentences like 'Joan's hair is red' and 'The wood of the sequoia is red' are partly, but not wholly, true. 'The European deer is reddish' and 'The European deer is sort of red' are to be explicated as 'It is partly true that the European deer is red'. 'The European deer is redder than the American deer' is presumably to be explicated as 'It is more true that the European deer is red than it is that the American deer is red'. ${ }^{10}$

Why should these usages suggest that we endorse partial truth? Friends of bivalence would say that 'red' can be used loosely, and that the standards for such usage are variable. So, 
for example, to call hair or wood 'red' would be to say something like the referent of this particular token of 'red' is red for hair, or red for wood. Under such loose usage, 'Joan's hair is red' and 'The sequoia's wood is red' are simply true. And bivalentists would say that 'The European deer is reddish', 'The European deer is sort of red', and 'The European deer is redder than the American deer' are true as they stand. On these construals, there is nothing partial about their truth. If they are wanting, it is in the area of precision.

Millgram considers sentences using modifiers like 'sort of' and '-ish' to be material mode counterparts of partial truths. 'The soil is reddish' says in the material mode what 'It is partly true that the soil is red' says in the formal mode. So, he thinks, we are already implicitly committed to partial truths when we use such language. His rationale is that reasoning involving sentences with such modifiers requires judgment, since the standards of application for such terms are variable, and both context and content dependent. Since 'The soil is reddish' and 'The brick is reddish' might deploy different standards of reddishness, we should not infer from the two sentences that the brick and the soil are the same color. This is so. From

(a) The soil is reddish

and

(b) The brick is reddish

it follows that

(c) The soil is reddish and the brick is reddish.

But to conclude that they are the same color takes a further step and an additional premise:

(d) If the soil is reddish and the brick is reddish, then the soil and the brick are the same color.

Whether to grant premise (d) depends on what criteria for being the same color are in effect. But even if we do not grant it, the inference from (a) and (b) to (c) goes through. 
To be sure, 'reddish' seems to have a more generous admissions policy than 'cerulean blue'. But no matter how strictly we regiment, items that instantiate a particular color predicate are typically not indiscriminable in color. Each color predicate covers a range of the visible spectrum. So the problem, if there is a problem, is not with extending our expressive range by 'sort of' and '-ish'. It is that indiscriminability is an unduly restrictive standard for coinstantiation. That is why we rarely, if ever, use it.

This suggests that locutions modified by ' -ish' and 'sort of' are perfectly respectable terms for use in flatly true sentences - sentences that can figure in classical logical inferences. They extend the expressive range of our limited vocabulary without affecting the logical capacities of the sentences in which they appear. There is evidently no mismatch between the sentences and the world. Sentences deploying such modifiers simply say something generic and imprecise about the way the world is.

Millgram evidently takes it that the goal of true representations is to replicate the world in words or in their mental counterparts. Since the world is messy and our cognitive resources are limited, that goal is unrealizable. So we resort to representations that do not quite match the world; they are only partly true. 'Consider a case where the mismatch between belief or statement and world amounts to a failure of bivalence. For example, I point out that the cloud up there is shaped like a horse's head. This is not, strictly speaking, true; no horse's head was every shaped quite like that.' (19) But the applicability of the predicate 'shaped like a horse's head' does not require the referent to be shaped exactly like the head of some specific horse, particularly when the predicate is applied to clouds. To think that the truth of the sentence would require an exact match is to misunderstand how our language functions. Millgram disagrees. He thinks that unless the representation exactly mirrors the corresponding fact, it is not entirely true.

The problem here evidently is vagueness. Once we diverge from the extension of 'shaped 
exactly like the head of some particular horse', there is no obvious answer to how far the predicate extends. 'Shaped like a horse's head' as applied to clouds is presumably answerable to looser standards than 'shaped like a horse's head' as applied to papier-maché models used in designing bridles. But if reasoning with bivalent sentences is supposed to proceed without judgment, Millgram believes, we could not register the difference between the two cases. This might seem doubtful. Clearly, one might think, 'The cloud is shaped like a horse's head' is sufficiently different from 'The model is shaped like a horse's head' that each could be bivalent, even though one was answerable to stricter standards than the other. Again, Millgram demurs. $\mathrm{He}$ is concerned, not with individual sentences or sentence types, but with categories of sentences. Membership in a category depends on a sentence's counterfactual or dispositional properties, not its syntax or semantics. Exactly what these categories and their associated properties are is unclear. But 'the category of sentences constructed using the predicate " . . is bald" is not bivalent, even though "Somebody or other is bald" is, realistically, inevitably true, and so bivalent.' (18). Evidently all sentences with the predicate ' . . . is shaped like a horse's head' must be subject to the same standards, for any of them to be bivalent.

To arrive at a fully true description of the cloud's shape, Millgram maintains, 'I could . . . replace the predicate "is shaped like a horse's head" with one precisely fitted to the shape of the cloud.' (20). This, he acknowledges, would be wildly impractical, if not impossible. To clutter my vocabulary with terms for the precise shape of everything I encounter (as well as the precise color, mass, distance from the Eiffel Tower, etc.) would make my language unusable as well as unlearnable. So, he maintains, we should welcome partial truths. But to think that truth requires precisely fitting the facts is to confuse truth with precision. Fully true descriptions often involve imprecise general terms. 'Fido is a mutt' is a true, albeit imprecise, description of Fido's ancestry. Maybe I could give a more precise characterization of Fido's pedigree; maybe not. But the truth 
of 'Fido is a mutt' does not depend on my ability to say anything more precise, or on my language's having the resources to say anything more precise. It depends on my language's having the resources to say something imprecise.

Elsewhere, Millgram indicates that we arrive at partial truth by backing off on accuracy. 'In the course of reasoning about how things stand, it is for the most part true that making inferential headway requires matching interlocking premises to one another. But experience teaches us that perfect matches are frequently hard to come by, and that matching means cutting corners on accuracy.' (57-58) The example he gives is a familiar type of physics problem.

A cow of mass $m_{1}$ is standing at a distance $d$ from a blade of grass of mass $m_{2}$; calculate the gravitational attraction exerted by the cow on the blade. Obviously, the correct way to approach the problem is to treat the cow as a sphere of homogeneous matter (or, possibly, a point-mass). There need be no pretense that the description of the cow as spherical is accurate, or even nearly accurate; one might say that it is approximately true, by way of saying that this is the correct approximation to use in solving the problem, but that would not thereby mean to imply that the cow is almost spherical. (58)

Representing the cow as a homogeneous sphere is the correct way to approach the problem. So 'In this sort of case, a cow is properly represented as a sphere' is true. But this is not to say that the representation is a correct approximation. The standard we use to evaluate approximations is closeness to the truth. Of two approximations of the average annual rainfall of Brazil, the better one is the one that is closer to the actual average annual rainfall. But even though a cylinder would more closely approximate the shape of a cow, it would not provide a better model for the problem at hand. Hence I am not in least inclined to say that 'The cow is spherical' is approximately true or that it is in any other way partly true. The sentence seems patently false. 
Moreover, the reason it is correct to represent the cow as a sphere is not, as Millgram claims, that we, or our introductory physics students, lack the mathematical tools needed to use an accurate description of the spatial distribution of the cow's mass. It is that for this sort of problem (these masses, at these distances, at this level of precision), the cow's divergence from sphericality and homogeneity does not matter. A knowledgeable, mathematically adept physicist would approach the problem in exactly the way the introductory students are supposed to, because she would know what sort of representation the problem calls for.11 (Elgin, 2004, 2010) Correctness here is not to be cashed out in terms of truth or closeness to the truth, for a more realistic representation of the cow would not be preferable.

Millgram seems to think that the true-false scale is the only scale along which we can assess the theoretical adequacy of claims. His reason for introducing partial truths is that assigning either 'true' or 'false' to certain sentences fails to do justice to their contribution to cognition. So, he maintains, something (or rather a large variety of things) between truth and falsity is required. But the true-false scale is not the only scale along which claims can assessed for theoretical adequacy. Precision, accuracy, informativeness, tractability, relevance, nonmisleadingness, and so forth are also important. A sentence then is assessed for theoretical adequacy along several different axes. If we recognize that these are different dimensions of assessment, we can preserve classical logic and recognize that a favorable assessment along one axis leaves open how a sentence is to be assessed along others.

\section{Conclusion}

I have argued that Millgram's reasons for introducing partial truths rest on untenable conceptions of logic and language. With tenable conceptions in place, it is possible and reasonable to retain a commitment to bivalence, or at least to resist Millgram's slide into a vast array of partial truths. Nevertheless, I want to acknowledge the feature of our theoretical 
reasoning that motivates Millgram's project. Much good reasoning involves considerations that are known not to be true and inference patterns that are known not to be classically valid. Sensitivity to contextual factors is often critical and hard to regiment. The point about inference patterns is not news. Inductive reasoning, analogical reasoning, probabilistic reasoning, and abductive reasoning are widely recognized as good ways to figure out how things are. The point about reasoning with false premises is perhaps more tendentious. But philosophers of science recognize that models afford insights into their targets, even though they are not accurate representations of their targets. Philosophers of literature argue that fictions afford insights into matters of fact. So even among analytic philosophers it is far from unthinkable that we can reason well with premises that are, and are known to be, false.

Still, it is important to keep in mind that when using premises that are not strictly true, inferences often have to be constrained. If, for example, a model of electron flow is inaccurate at very low temperatures, one should refrain from using it when reasoning about what happens near absolute zero. This is a familiar point. Moreover, when we reason deductively, we not infrequently restrict the range of our quantifiers. The premise of 'All the glasses are empty, so it's time for another round' is true, only if the scope of the quantifier is restricted. So we restrict it. Being interested only in the members of our party, we restrict the scope of 'all' to apply exclusively to their glasses, not all the glasses in the world. This is unproblematic, for anyone who knows how to make or understand the inference knows the relevant scope restriction.

The introduction of a plethora of partial truths strikes me as unjustified and unwise. The true/false axis is not the only axis along which sentences and beliefs can be evaluated, and it is not always the most important one. We need to concern ourselves with whether a sentence or belief is relevant, whether it is informative, whether it is cast at the appropriate level of generality, whether it is supported by the evidence, whether it is misleading or gives rise to 
misleading implicatures. Just knowing its truth value does not tell us these things. But neither would just knowing that it is partly true. If we know that a sentence is partly true, Millgram believes, we can be confident that its failure to match the world does not undermine its functioning in a given chain of reasoning. But once we have repudiated philosophical analysis and conceded that there are indefinitely many ways unproblematic mismatches can occur, we lose any hope of understanding when or how or why a mismatch does or does not matter.

Catherine Z. Elgin

Harvard University 


\section{References}

Cartwright, N (1983). How the Laws of Physics Lie. Oxford: Clarendon Press.

Dummett, M. (1978). Truth and Other Enigmas. Cambridge MA: Harvard University Press.

Elgin, C. (2010). 'Telling Instances' Beyond Mimesis and Convention. Dordrecht: Springer Verlag.

Elgin, C. (2004). 'True Enough'. Philosophical Issues 14: 271-281.

Frege, G. (1997). 'Grundgesetze der Arithmetik Volume1.' In: The Frege Reader - Beaney, M. ed. Oxford:Blackwell, 195-223.

Harman, G. Change in View. Cambridge MA: MIT Press.

Lewis, D. (1997). 'Logic for Equivocators,' in Papers in Philosophical Logic. Cambridge: Cambridge University Press. 97-110.

Millgram, E. (2009). Hard Truths. Malden: Wiley Blackwell.

Ullian, J. and Goodman, N. (1977). 'Truth about Jones'. Journal of Philosophy 74: 317-338.

Yablo, S (unpublished) 'The Truth and Something but the Truth'.

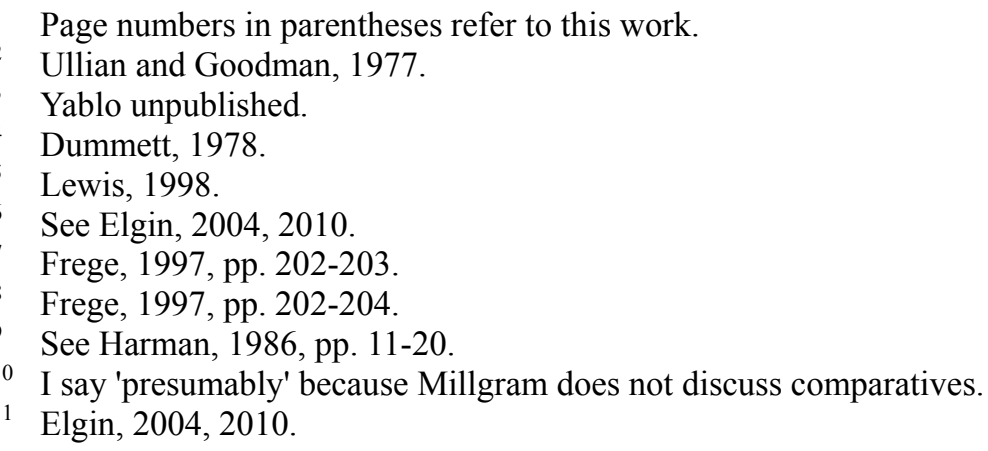

